\title{
PROTEÍNA PROTEGIDA DE SOJA E O DESEMPENHO DE CORDEIROS EM CONFINAMENTO
}

(Protected Soy Protein and the performance of finishing ram lambs)

\author{
ANDRIGUETTO, J.L. ${ }^{1}$; CAVASSIN, E. ${ }^{2}$ \\ ${ }^{1}$ Departamento de Zootecnia - SCA - UFPR; \\ ${ }^{2}$ Curso de Pós-Graduação em Ciências Veterinárias, UFPR.
}

\begin{abstract}
RESUMO - O presente trabalho compara a eficiência de três formas de proteína de soja na alimentação de cordeiros confinados. Utilizaram-se 21 cordeiros machos, distribuídos em blocos ao acaso em três grupos de tratamento: farelo de soja (FS) $(n=7)$; soja integral tostado (SIT) $(n=7)$; proteína protegida de soja (PPS) $(n=7)$. As três rações foram balanceadas de acordo com o NRC (1985) e continham os mesmos teores de proteína bruta (18\%), energia metabolizável $(2370 \mathrm{kcal} / \mathrm{kg})$ e fibra em detergente neutro (38\%), diferindo quanto à fonte principal de proteína. Os resultados médios obtidos para ganho de peso, consumo de ração e conversão alimentar não diferiram significativamente $(P>0,05)$. Quanto às características de carcaça, não foram observadas diferenças significativas $(P>0,05)$ para o peso de carcaça quente e para a área de olho de lombo. A taxa de rendimento de carcaça foi significativamente menor $(P=0,05)$ com PPS. A porcentagem de gordura perirenal em relação ao peso de carcaça foi menor $(P=0,07)$ com PPS do que com FS e SIT, que não diferiram entre si. Não foram observadas diferenças significativas nos níveis de glucose plasmática, porém os níveis plasmáticos de uréia aumentaram consideravelmente entre a segunda e a terceira semana após o início dos tratamentos, sendo que a elevação da concentração de uréia plasmática foi significativamente menor $(P<0,05)$ nos animais alimentados com FS. Assim sendo, a PPS mostrou-se menos eficiente para o crescimento de cordeiros.
\end{abstract}

Palavras chave: borregos, cordeiros, farelo de soja, proteína protegida de soja, soja tostada.

ABSTRACT - The objective of the present work was to evaluate the efficiency of three forms of soy protein with different contents of rumen degradable protein on performance, carcass characteristics and plasma urea and glucose levels of finishing lambs. Ram lambs (21) were assigned to three treatments, on a random block design: soybean meal $(S M)(n=7)$; roasted whole soybean (RWS) $(n=7)$; and protected soybean protein (PSP) $(n=7)$. The three experimental diets were formulated to contain the same levels of crude protein $(18 \%)$, metabolizable energy $(2370 \mathrm{kcal} / \mathrm{kg})$, neutral-detergent fiber $(38 \%)$, differing only in the main protein source. Average daily gain, feed intake and feed efficiency were not affected by treatment $(P>0.05)$. There were also no effects $(P>0.05)$ on carcass weight and Longissimus dorsi muscle area. The carcass yield of lambs receiving PSP was significantly lower $(P=0.05)$ than that observed with other sources of protein. The percentage of perirenal fat was also lower $(P=0.07)$ for animals fed with PSP. There was no effect on plasma glucose concentration. Plasma urea levels, however, were increased after the second week of the beginning of the experiment, and that increase was significantly lower $(P<0.05)$ with $S M$ than with RWS or PSP. PSP has apparently decreased the performance of growing lambs with reduced deposition of muscle tissue and efficiency of energy and protein metabolism.

Key words: lambs, protected soy protein, soybean meal, roasted whole soybean.

Correspondência para: ANDRIGUETTO, J.L., Rua dos Funcionários, 1540, Curitiba - PR - 80050-030; jluciano@agrarias.ufpr.br. 


\section{Introdução}

Melhoramento genético, novas práticas de manejo e redução do teor de gordura da carcaça têm levado os ovinos de corte a apresentarem maior taxa de crescimento, maior ganho de peso, melhor conversão alimentar e maior rendimento de carcaça, com exigências nutricionais consequentemente maiores.

Entre os nutrientes a serem supridos, a proteína tem recebido atenção especial, pois sabe-se que a proteína microbiana, sintetizada no rúmen, não atende as exigências do hospedeiro de elevada capacidade de produção, principalmente se considerada a disponibilidade de aminoácidos. A proteína não degradável de forragens normalmente apresenta baixo valor biológico. Assim sendo, para ruminantes de alta capacidade de produção, torna-se importante a suplementação de quantidades adicionais de proteína de alto valor biológico e baixa degradabilidade no rúmen.

Com este objetivo, tem-se buscado o tratamento das fontes protéicas das dietas com vários agentes como calor, tanino, formaldeído e outros, visando diminuir a degradabilidade ruminal da proteína, porém sem prejudicar sua digestibilidade para o animal.

No presente trabalho, foi utilizado um produto do processamento do soja, para cordeiros em confinamento, em comparação com fontes tradicionais de proteína, quais sejam o farelo de soja e soja integral tostada. Os animais tiveram seu desempenho avaliado quanto a ganho de peso, consumo alimentar, conversão alimentar, características de carcaça, e níveis plasmáticos de glucose e uréia.

\section{Material e Métodos}

O experimento foi conduzido no setor de Ovinocultura do Centro de Estações Experimentais do Canguiri, da Universidade Federal do Paraná, CuritibaPr. Foram utilizados 21 cordeiros machos inteiros, mestiços Suffolk, com idade aproximada de 100 dias e peso inicial de $23,9 \mathrm{~kg}$. Após a verificação da higidez dos animais, os mesmos foram alojados em baias individuais cobertas, de $1,8 \mathrm{~m}^{2}$, equipadas com bebedouros automáticos $\mathrm{e}$ cochos individuais externos, onde receberam as rações experimentais em duas refeições diárias. Os tratamentos foram iniciados após um período de adaptação de 14 dias.

A proteína protegida de soja aqui testada é resultante de tratamento térmico após a inclusão de 2,5\% de um açúcar redutor, de modo que ocorre reação de Maillard de forma limitada, reduzindo a degradabilidade ruminal da proteína. A urease encontrada foi de 0,15 , de modo que se consideram inativados os princípios antinutricionais. Convém ressaltar que o nível de urease não reflete necessariamente a extensão da reação de Maillard e consequente redução na disponibilidade da proteína.

Os animais foram distribuídos em três tratamentos, com 7 repetições por tratamento, num delineamento experimental de blocos ao acaso. As rações foram calculadas de modo a serem isoprotéicas e isocalóricas, diferindo apenas quanto à fonte principal de proteína, quais sejam farelo de soja (FS), soja integral tostada (SIT) ou proteína protegida de soja (PPS) (TABELA 1).

TABELA 1 - COMPOSIÇÃO DAS DIETAS EXPERIMENTAIS DOS CORDEIROS.

\begin{tabular}{ccccccc}
\hline & MILHO & FARELO & SOJA & PROTEÍNA & FENO DE \\
& MOÍDO & DE SOJA & MISTURA \\
INTEGRAL & PROTEGIDA & ALFAFA & $\%$ & MINERAL \\
$\%$ & $\%$ & $\%$ & $\%$ & $\%$ \\
\hline FS & 48,00 & 17,00 & - & - & 30,00 & 5,00 \\
SIT & 44,50 & 5,50 & 15,00 & - & 30,00 & 5,00 \\
PPS & 44,00 & - & - & 17,00 & 34,00 & 5,00 \\
\hline
\end{tabular}

A composição das matérias-primas está descrita na tabela 2 . As rações experimentais foram balanceadas de acordo com o NRC (1985), de modo a atender as exigências de um animal de 25 $\mathrm{kg}$, com um consumo médio diário de $4 \%$ 
Proteína protegida de soja e o desempenho de cordeiros em confinamento

do peso vivo, permitindo um ganho médio diário entre 200 e $250 \mathrm{~g}$ (TABELA 2).

Os animais foram pesados semanalmente, desde o início do experimento até o $39^{\circ}$ dia. O consumo de matéria fresca da ração foi avaliado pela pesagem diária da quantidade fornecida e pela pesagem semanal das sobras, que eram coletadas diariamente. No $40^{\circ}$ dia, após 14 horas de jejum, os cordeiros foram pesados e abatidos pelo processo de sangria, para ser realizada a avaliação do rendimento e características de carcaça. Executados o abate e a evisceração, a carcaça quente foi pesada e a gordura perirenal foi dissecada e imediatamente pesada. Após um período de resfriamento a $4^{\circ} \mathrm{C}$ de 28 horas, as áreas de olho de lombo direita e esquerda foram fotografadas ao nível da $12^{\mathrm{a}}$ costela. Os programas Calibrate e Farmworks foram utilizados para o cálculo das áreas de olho de lombo.

TABELA 2 - NÍVEIS NUTRICIONAIS DAS MATÉRIAS-PRIMAS E RAÇÕES EXPERIMENTAIS.

\begin{tabular}{lcccccc}
\hline & PB \% & PNDR \% & EE \% & RM \% & FDN \% & $\begin{array}{c}\text { EM } \\
\text { Mcal/kg }\end{array}$ \\
\hline Fubá de milho & 8,88 & 5,06 & 5,15 & 1,52 & 34,87 & 3,12 \\
Farelo de soja & 47,03 & 16,93 & 3,49 & 6,81 & 18,21 & 2,09 \\
Soja tostado & 39,48 & 16,20 & 22,61 & 5,29 & 30,89 & 2,27 \\
Proteína P. de soja & 46,40 & 27,80 & 1,59 & 6,90 & 28,36 & 2,09 \\
Feno de alfafa & 19,22 & 8,65 & 4,64 & 12,46 & 59,81 & 1,81 \\
Ração FS & 17,87 & 7,85 & 4,43 & 5,61 & 37,61 & 2,38 \\
Ração SIT & 18,14 & 8,20 & 7,24 & 5,56 & 38,90 & 2,37 \\
Ração PPS & 18,18 & 9,80 & 4,09 & 6,06 & 40,32 & 2,33 \\
\hline
\end{tabular}

Para a análise dos níveis plasmáticos de glucose e uréia, foram coletadas amostras de sangue nos dias 1, 1529 e 39 após o início do experimento. As amostras foram colhidas por punção da veia jugular, na metade do intervalo entre as duas refeições diárias. O sangue foi coletado com heparina como anticoagulante e imediatamente centrifugado para a separação do plasma. Este foi coletado e congelado a $-20^{\circ} \mathrm{C}$. Os níveis plasmáticos de glucose e uréia foram determinados por kits comerciais (Labtest Diagnóstica S.A.) de sistemas enzimáticos

\section{colorimétricos.}

Os resultados obtidos foram analisados estatisticamente por análise de variância e as médias foram comparadas pelo teste de Tukey, utilizando-se o Sistema para Análises Estatísticas e Genéticas SAEG versão 5.0 (UNIVERSIDADE FEDERAL DE VIÇOSA, 1982).

\section{Resultados e Discussão}

Não se observou efeito significativo $(P>0,05)$ dos tratamentos sobre o peso vivo final, ganho de peso total e ganho de peso médio diário (TABELA 3).

TABELA 3 - PESO MÉDIO INICIAL, PESO MÉDIO FINAL, GANHO DE PESO TOTAL E GANHO MÉDIO DIÁRIO DE CORDEIROS CONFINADOS, ALIMENTADOS COM TRÊS FONTES DE PROTEÍNA DE SOJA: FARELO DE SOJA (FS), SOJA INTEGRAL TOSTADA (SIT) E PROTEÍNA PROTEGIDA DE SOJA (PPS)

\begin{tabular}{llll}
\hline & \multicolumn{1}{c}{ FS } & \multicolumn{1}{c}{ SIT } & \multicolumn{1}{c}{ PPS } \\
\hline Peso inicial $(\mathrm{kg})$ & $23,87 \pm 1,49 \mathrm{a}$ & $23,87 \pm 2,00 \mathrm{a}$ & $23,94 \pm 2,34 \mathrm{a}$ \\
Peso final $(\mathrm{kg})$ & $40,18 \pm 2,63 \mathrm{a}$ & $39,04 \pm 2,38 \mathrm{a}$ & $38,86 \pm 3,17 \mathrm{a}$ \\
Ganho total $(\mathrm{kg})$ & $16,31 \pm 2,30 \mathrm{a}$ & $15,17 \pm 1,19 \mathrm{a}$ & $14,91 \pm 1,85 \mathrm{a}$ \\
Ganho médio diário $(\mathrm{g})$ & $418,13 \pm 58,98 \mathrm{a}$ & $389,00 \pm 30,65 \mathrm{a}$ & $382,41 \pm 47,45 \mathrm{a}$ \\
\hline
\end{tabular}

Médias nas linhas seguidas de letras diferentes diferem ao nível de $5 \%$ de probabilidade 
Apesar de vários autores (VEIRA et al., 1985; VEIRA et al., 1988; TAYER e BRYANT, 1991; STEEN, 1989) terem demonstrado melhor ganho de peso em animais alimentados com fontes de proteína de baixa degradabilidade, CLARK et al. (1992) obtiveram resultados não satisfatórios, atribuindo-os à redução da síntese de proteína microbiana, à baixa disponibilidade intestinal da proteína protegida ou, ainda, à limitação da composição de aminoácidos da proteína protegida. Segundo HUSSEIN e JORDAN (1991a), a maior quantidade de proteína que escapa da degradação ruminal pode provocar uma redução na síntese de proteína microbiana no rúmen. TAMMINGA (1979) justifica que essa menor produção de biomassa ruminal pode ser causada por carência de nitrogênio amoniacal. Entretanto, ECK et al. (1988) afirmam que a gravidade da deficiência de nitrogênio amoniacal é grandemente influenciada pelo tipo de volumoso fornecido. GIBB e BAKER (1987), comparando a resposta de novilhos recebendo ou não proteína protegida juntamente com silagem de milho ou feno de alfafa observaram melhores resultados com as dietas a base de silagem, atribuindo a diferença a um aumento da digestibilidade da matéria orgânica da silagem em relação ao feno. HUSSEIN e JORDAN (1991b) também não observaram diferença significativa para o ganho de peso de cordeiros que receberam farinha de peixe em substituição ao farelo de soja, utilizando o feno de alfafa como volumoso. A proteína protegida de soja pode ainda ter sido superprotegida, resultando em baixa digestibilidade intestinal (CHALUPA, 1984).

Não se observou efeito significativo dos tratamentos sobre o consumo de matéria fresca ou seca (TABELA 4). Relatos sobre o efeito da inclusão de proteína de baixa degradabilidade ruminal na ingestão mostram resultados diversos. VAN SOEST (1994) relata que em $85 \%$ dos experimentos em que houve maior ganho de peso, a ingestão de matéria-seca estava aumentada. STEEN (1988) observou que o consumo de silagem por bovinos tende a aumentar somente quando a suplementação proteica promove um aumento da digestibilidade da matéria orgânica. STEEN (1989) não observou alterações no consumo de silagem por novilhos, com a utilização de níveis crescentes de farinha de peixe. Já VEIRA et al. (1990) observaram redução no consumo de silagem, porém sem redução na ingestão total de matéria-seca. De forma semelhante, TAN e BRYANT (1991), trabalhando com cordeiros alimentados com feno e farinha de peixe, observaram que o consumo total de matéria-seca não foi deprimido com a utilização de altos níveis de concentrado contendo farinha de peixe.

Ao contrário do observado em cordeiros suplementados com farinha de peixe (TAN e BRYANT, 1991; ADAM, et al., 1982), a proteína protegida de soja e a soja integral tostada não favoreceram significativamente a conversão alimentar (TABELA 4).

TABELA 4 - CONSUMO MÉDIO TOTAL E DIÁRIO DE MATÉRIA FRESCA (MF) DA RAÇÃO, CONSUMO MÉDIO DIÁRIO DE MATÉRIA SECA, EXPRESSO EM PERCENTUAL DE PESO VIVO (\%PV) E CONVERSÃO ALIMENTAR.

\begin{tabular}{llll}
\hline & \multicolumn{1}{c}{ FS } & \multicolumn{1}{c}{ SIT } & PPS \\
\hline Consumo Total de MF (kg) & $58,23 \pm 1,00$ a & $57,66 \pm 1,87$ a & $58,54 \pm 2,27$ a \\
Consumo médio diário de MF (kg) & $1,49 \pm 0,03$ a & $1,48 \pm 0,05$ a & $1,50 \pm 0,06$ a \\
Consumo médio diário de MS (\%PV) & $4,16 \pm 0,49$ a & $4,19 \pm 0,19$ a & $4,27 \pm 0,27$ a \\
Conversão alimentar & $3,63 \pm 0,49$ a & $3,81 \pm 0,26$ a & $3,92 \pm 0,46$ a \\
\hline
\end{tabular}

Médias nas linhas seguidas de letras diferentes diferem ao nível de $5 \%$ de probabilidade

Os tratamentos não afetaram significativamente $(P<0,05)$ o peso de carcaça quente nem a área de olho de lombo. O rendimento de carcaça mostrou uma forte tendência a redução por efeito do uso de proteína protegida de soja 
Proteína protegida de soja e o desempenho de cordeiros em confinamento

$(P=0,05)$ quando comparado com aquele dos outros tratamentos. De forma semelhante, houve uma tendência para redução da quantidade de gordura perirenal $(P=0,07)$ avaliada como percentagem da carcaça quente, nos animais tratados com proteína protegida de soja (TABELA 5).

Ao contrário de BEERMAN et al. (1986), que obtiveram melhores características de carcaça com o uso de proteína de baixa degradabilidade, neste trabalho tal resultado, de modo geral, não foi significativo. Resultado semelhante foi observado por VEIRA et al. (1988), STEEN (1988) e STEEN (1989). A proteína protegida de soja mostrou-se aparentemente menos eficiente para a produção de carne de cordeiros, tanto pela menor deposição de tecido muscular, conforme sugerido pelo menor rendimento de carcaça, como pela menor eficiência do metabolismo energético e protéico, conforme sugerido pela menor deposição de gordura perirenal.

TABELA 5 - PESO DE CARCAÇA QUENTE, RENDIMENTO DE CARCAÇA, GORDURA PERIRENAL (EXPRESSA EM GRAMAS E EM PERCENTAGEM DA CARCAÇA QUENTE) E ÁREA DE OLHO DE LOMBO DIREITA E ESQUERDA (EM $\mathrm{CM}^{2}$ ).

\begin{tabular}{llll}
\hline \multicolumn{1}{c}{ CARACTERISTICAS } & \multicolumn{1}{c}{ FS } & \multicolumn{1}{c}{ SIT } & \multicolumn{1}{c}{ PPS } \\
\hline Peso de carcaça quente $(\mathrm{kg})$ & $18,39 \pm 1,43 \mathrm{a}$ & $18,21 \pm 1,25 \mathrm{a}$ & $16,73 \pm 1,63 \mathrm{a}$ \\
Rendimento de carcaça $(\%)^{*}$ & $48,69 \pm 2,88 \mathrm{a}$ & $49,30 \pm 1,53 \mathrm{a}$ & $45,45 \pm 2,31 \mathrm{~b}$ \\
Gordura perirenal $(\mathrm{g})$ & $152 \pm 26 \mathrm{a}$ & $158 \pm 38 \mathrm{a}$ & $118 \pm 20 \mathrm{a}$ \\
Gordura perirenal $(\%)^{* *}$ & $0,83 \pm 0,12 \mathrm{a}$ & $0,86 \pm 0,16 \mathrm{a}$ & $0,71 \pm 0,07 \mathrm{a}$ \\
Área de olho de lombo esquerda $\left(\mathrm{cm}^{2}\right)$ & $16,99 \pm 2,80 \mathrm{a}$ & $17,18 \pm 1,73 \mathrm{a}$ & $15,59 \pm 1,57 \mathrm{a}$ \\
Área de olho de lombo esquerda $\left(\mathrm{cm}^{2}\right)$ & $16,64 \pm 2,50 \mathrm{a}$ & $17,05 \pm 1,95 \mathrm{a}$ & $15,93 \pm 1,79 \mathrm{a}$ \\
\hline
\end{tabular}

Médias nas linhas seguidas de letras diferentes diferem ao nível de $5 \%$ de probabilidade

${ }^{*} \mathrm{P}=0,05 ;{ }^{* *} \mathrm{P}=0,07$

Não se observou efeito significativo das fontes protéicas sobre o nível de glucose plasmática, tanto entre tratamentos como dentro dos tratamentos, ao longo do período experimental (TABELA 6), mostrando que o padrão de normalidade do metabolismo não foi alterado pelas dietas experimentais. Resultado semelhante foi observado por STEEN (1988).

TABELA 6 - VARIAÇÃO DO NÍVEL DE GLUCOSE PLASMÁTICA (MG/DL) ENTRE E AO LONGO DOS TRATAMENTOS.

\begin{tabular}{|c|c|c|c|}
\hline & FS & SIT & PPS \\
\hline $1^{\text {o. }}$ dia & $66,81 \pm 7,24 \mathrm{a}, \mathrm{A}$ & $70,55 \pm 5,26 \mathrm{a}, \mathrm{A}$ & $68,97 \pm 6,88 \mathrm{a}, \mathrm{A}$ \\
\hline $15^{\circ}$ dia & $78,34 \pm 4,75 a, A$ & $81,45 \pm 6,23 a, A$ & $78,57 \pm 3,95$ a, $A$ \\
\hline $29^{\circ}$ dia & $78,43 \pm 6,46 \mathrm{a}, \mathrm{A}$ & $80,19 \pm 6,76$ a,A & $75,79 \pm 3,98 a, A$ \\
\hline $39^{\circ}$ dia & $74,41 \pm 3,38 \mathrm{a}, \mathrm{A}$ & $74,44 \pm 6,48 \mathrm{a}, \mathrm{A}$ & $74,13 \pm 3,55 a, A$ \\
\hline
\end{tabular}

Médias nas linhas seguidas de letras minúsculas diferem ao nível de $5 \%$ de probabilidade. Médias nas colunas seguidas de letras maiúsculas diferem ao nível de $5 \%$ de probabilidade.

Os níveis médios de uréia plasmática mantiveram-se relativamente estáveis até a segunda semana após o início dos tratamentos, apresentaram uma rápida e significativa elevação entre a segunda e a terceira semanas, mantendo-se neste nível até o final do fornecimento da dieta experimental. Comportamento semelhante foi observado em todos os tratamentos, sendo que o aumento da concentração de uréia no plasma foi significativamente menor $(P<0,05)$ por efeito do tratamento controle com farelo de soja (FS) em relação aos tratamentos com soja integral tostado (SIT) e com proteína protegida de soja (PPS), que não apresentaram diferenças significativas entre si (TABELA 7). 
TABELA 7 - VARIAÇÃO DO NÍVEL DE URÉIA PLASMÁTICA (Mg/dL) ENTRE E AO LONGO DOS TRATAMENTOS.

\begin{tabular}{llll}
\hline & \multicolumn{1}{c}{ FS } & \multicolumn{1}{c}{ SIT } & \multicolumn{1}{c}{ PPS } \\
\hline $1^{\text {0. }}$ dia & $36,21 \pm 3,14 \mathrm{a}, \mathrm{A}$ & $44,54 \pm 4,14 \mathrm{~b}, \mathrm{~A}$ & $40,16 \pm 4,59 \mathrm{a}, \mathrm{b}, \mathrm{A}$ \\
$15^{\circ}$ dia & $36,79 \pm 4,02 \mathrm{a}, \mathrm{A}$ & $43,63 \pm 4,22 \mathrm{~b}, \mathrm{~A}$ & $44,47 \pm 3,89 \mathrm{~b}, \mathrm{~A}$ \\
$29^{\circ}$ dia & $47,33 \pm 3,76 \mathrm{a}, \mathrm{B}$ & $54,21 \pm 5,51 \mathrm{~b}, \mathrm{~B}$ & $57,38 \pm 3,35 \mathrm{~b}, \mathrm{~B}$ \\
$39^{\circ}$ dia & $45,59 \pm 3,32 \mathrm{a}, \mathrm{B}$ & $57,74 \pm 4,86 \mathrm{~b}, \mathrm{~B}$ & $58,09 \pm 4,78 \mathrm{~b}, \mathrm{~B}$ \\
\hline
\end{tabular}

Médias nas linhas seguidas de letras minúsculas diferem ao nível de $5 \%$ de probabilidade. Médias nas colunas seguidas de letras maiúsculas diferem ao nível de $5 \%$ de probabilidade.

ROSELER et al. (1993), trabalhando com dietas isoprotéicas e balanceadas em termos de proteína degradável e não degradável no rúmen, observaram aumento da concentração plasmática de uréia, em vacas lactantes, quando a dieta fornecida apresentava excesso de qualquer das frações protéicas. Os maiores níveis de uréia plasmática, observados no presente trabalho, por efeito dos tratamentos SIT e PPS, em relação ao $\mathrm{FS}$, podem ter ocorrido, em parte, devido a um excesso de proteína não degradável no rúmen ou, de acordo com ABDELGADIR et al. (1996), devido a um maior desequilíbrio de aminoácidos alcançando o intestino delgado.

\section{Conclusões}

A hipótese de que a fonte de proteína de soja testada melhoraria o desempenho dos cordeiros em fase de crescimento e com maior produção de carne magra, por elevar o valor biológico da proteína que alcança o intestino delgado do animal, foi negada pelos resultados zootécnicos obtidos.

Ao contrário do que se esperava, os dados obtidos são compatíveis com uma menor disponibilidade de nutrientes para os cordeiros em crescimento que receberam a dieta com a proteína de soja testada.

Esta menor disponibilidade de nutrientes teve provavelmente duas origens:

a) menor rendimento da fermentação ruminal;

b) baixo valor biológico complementar da fonte de proteína testada, em relação ao produto esperado.
Maiores informações sobre a degradabilidade ruminal, a digestibilidade total e o valor biológico da fração não degradada no rúmen da fonte protéica testada são necessárias para a completa avaliação de sua viabilidade.

\section{Referências}

ABDELGADIR, I. E. O.; MORRIL, J. L.; HIGGINS, J. J. Effect of roasted soybeans and corn on performance and ruminal and blood metabolites of dairy calves. Journal of Dairy Science, Savoy, v. 79, n. 3, p. 465-474, 1996.

ADAM, A. I.; HOGUE, D.; MAGEE, B. H. Protein sources in diets of rapidly growing lambs. Journal of Animal Science, Savoy, v. 55, n. 1, p. 401-412, 1982.

BEERMANN, D.H.; HOGUE, D.E.; FISHELL, V.K.; DALRYMPLE, R.H.; RICKS, C.A. Effects of cimatecol and fishmeal on performance, carcass characteristics and skeletal muscle growth in lambs. Journal of Animal Science, v. 62, p. 370-380, 1986.

CHALUPA, W. Protein symposium. Journal of Dairy Science, Savoy, v. 67, n. 5, p. 11341146, 1984.

CLARK, J. H.; KLUSMEYER, T. H.; CAMERON, M. R. Nitrogen metabolism and amino acid nutrition in dairy cattle: microbial protein synthesis and flows of nitrogen fractions to the duodenum of dairy cows. Journal of Dairy Science, Savoy, v. 75, n. 8, p. 2304-2323, 1992.

ECK, T. P.; BARTLE, S. J.; PRESTON, R. L. et al. Protein source and level for incoming feedlot cattle. Journal of Animal Science, Savoy, v. 66, p. 1871-1876, 1988.

GIBB, M. J.; BAKER, R. D. Performance of young steers offered silage or thermoammoniated hay with or without a fish meal supplement. Animal Production, Pencaitland, v. 45, p. 371-381, 1987. 
Proteína protegida de soja e o desempenho de cordeiros em confinamento

HUSSEIN, H. S.; JORDAN, R. M. Fish meal as a protein supplement in ruminant diets: a review. Journal of Animal Science, Savoy, v. 69 , p. 2147-2156, 1991a.

HUSSEIN, H. S.; JORDAN, R. M. Fish meal as a protein supplement in finishing lamb diets. Journal of Animal Science, Savoy, v. 69, p. 2115-2122, $1991 \mathrm{~b}$.

ROSELER, D. K.; FERGUSON, J. D.; SNIFFEN, C. J. Dietary protein degradability effects on plasma and milk urea nitrogen and milk nonprotein nitrogen in Holstein cows. Journal of Dairy Science, Savoy, v. 76, n. 2, p. 525-534, 1993.

STEEN, R. W. J. The effect of supplementing silage-based with soya bean and fish meals for finishing beef cattle. Animal Production, Pencaitland, v. 46, p. 43-51, 1988.

STEEN, R. W. J. A comparison of soyabean, sunflower and fish meals as protein supplements for yearling cattle offered grass silage based diets. Animal Production, Pencaitland, v. 48, p. 81-89, 1989.

TAMMINGA, S. Protein degradation in the forestomachs of ruminants. Journal of Animal Science, Savoy, v. 49, n. 6, p. 16151632, 1979.

Recebido para publicar: 12/05/2002

Aprovado:

$20 / 06 / 2002$
TAN, P. V.; BRYANT, M. J. The effect of dietary supplements of fish meal on the voluntary feed intake of store lambs. Animal Production, Pencaitland, v. 52, p. 271-278, 1991.

TAYER, S. R.; BRYANT, M. J. The response of store lambs to dietary supplements of fish meal. Animal Production, Pencaitland, v. 47, p. 393-399, 1991.

UNIVERSIDADE FEDERAL DE VIÇOSA SAEG: sistema de análises estatísticas e genéticas. Viçosa, 1982. 49 p. Versão 5.0.

VAN SOEST, P. J. Nutritional ecology of the ruminant. 2.ed. New York: Cornell University Press, 1994. 476p.

VEIRA, D. M.; BUTLER, G.; IVAN, M.; PROULX, J. G. Utilization of grass silage by cattle: effect of barley and fishmeal supplements. Canadian Journal of Animal Science, Ottawa, v. 65, p. 897-901, 1985.

VEIRA, D. M.; PROULX, J. G.; BUTLER, G.; FORTIN, A. Utilization of grass silage by cattle: further observations on the effect of fishmeal. Canadian Journal of Animal Science, Ottawa, v. 68, p. 1225-1235, 1988.

VEIRA, D. M.; PROULX, J. G.; SEOANE, J. R. Performance of steers fed grass silagewith or without supplements of soybean meal, fish meal and barley. Canadian Journal of Animal Science, Ottawa, v. 70, p. 313-317, 1990. 